\title{
Making Medical Teaching Interactive: Catering Learning Needs in Radiology
}

\author{
${ }^{1}$ Ilona Petsch, ${ }^{2}$ Aglaé González Velasco, ${ }^{3}$ Walter Heindel, ${ }^{4}$ Boris Buerke \\ 1,2,3,4 University of Muenster, and University Hospital Muenster/Department of Clinical Radiology, Medical \\ Faculty
}

\begin{abstract}
We attempt to explore how to integrate medical students learning needs in teaching imaging courses in radiology through means of interaction. An interactive teaching approach will allow radiologists as medical teachers to flexibly cater student learning needs face to face. An interactive teaching approach supports addressing learning needs through dialogue, while being efficient for clinical teaching and effective for medical learning. As part of an ongoing study the following initial results can be assumed: By interacting, radiologists and students can negotiate learning needs in a needoriented approach as to tailor teaching objectives to demand; By interacting, radiologists and students can rapidly bring across learning and teaching objectives besides a busy clinical routine; By cooperating with co-teachers of other imaging disciplines, radiologists can tailor clinical content to student learning needs, and avoid redundancies within medical education. Interacting could encourage medical students to learn about image interpreting and demonstrating basic clinical patterns in imaging and case reporting; Interacting while negotiating learning and teaching objectives, could be time-efficient due to staff shortage, high workload, numerous case conferences and limited teaching time in clinical routine at teaching and university hospitals; Cooperating with co-teachers interfacing with radiology would add to tailor content to learning needs in understanding common indications and contraindications for diagnostic work-up, clinical and therapeutic decisions in clinical and interventional radiology, and to reach a consensus avoiding redundancies.
\end{abstract}

Keywords: educational needs, imaging courses, interaction, medical education, medical students. 